\title{
A HIPÓTESE DE KUZNETS PARA OS ESTADOS BRASILEIROS: EVIDÊNCIAS EMPÍRICAS DE DADOS EM PAINEL PARA 0 PERÍODO 1999-2014',2
}

\author{
Luciano Balbino dos Santos 3 \\ Tito Belchior Silva Moreira ${ }^{4}$
}

\begin{abstract}
Este trabalho investiga a relação entre crescimento econômico e desigualdade de renda, testando a validade da hipótese de Kuznets para as 27 Unidades Federativas do Brasil, a partir de um painel de dados com frequência anual, compreendendo o período 1999-2014. Os procedimentos metodológicos seguem duas etapas. Na primeira, aplica-se o teste de causalidade de Granger para as variáveis de interesse: 0 índice de Gini, medindo a desigualdade, e a renda domiciliar per capita média, como proxy para o crescimento econômico. Na segunda, fazem-se estimativas com painel de efeitos fixos e um painel dinâmico com o uso de instrumentos, estabelecendo a desigualdade como variável dependente em função da renda per capita, educação, taxa de inflação e de outras variáveis de controle importantes para explicar essa relação. Os resultados obtidos sinalizam com clareza um comportamento oposto a hipótese de Kuznets. Isto é, a desigualdade inicialmente diminui com o aumento da renda, mas, em seguida, quando a renda cresce de forma mais significativa, ela também assume uma trajetória de crescimento.
\end{abstract}

Palavras-chave: desigualdade e crescimento; teste de Granger; hipótese de Kuznets.

\section{THE KUZNETS HYPOTHESIS FOR THE BRAZILIAN STATES: EMPIRICAL EVIDENCE OF PANEL DATA FOR THE PERIOD FROM 1999 TO 2014}

This work investigated the relationship between economic growth and income inequality, testing the validity of the Kuznets hypothesis for the twenty seven federative units of Brazil, from a database with annual frequency, comprising the period from 1999 to 2014. The methodology is divided into two steps. In the first, we apply the Granger causality test to the variables of interest; Gini index, measuring inequality and average per capita household income, as a proxy to economic growth. In the second, we estimate a regression, establishing inequality as a dependent variable as a function of per capita income, education, inflation rate, and other important control variables to explain this relationship. The results obtained clearly signal a behavior opposite to the Kuznets hypothesis. That is, inequality initially decreases with increasing income, but then, when income grows more significantly, it also assumes a path of growth.

Keywords: inequality and growth; Granger test; hypothesis of Kuznets.

1. DOI: http://dx.doi.org/10.38116/ppp54art06

2. Os autores agradecem os pertinentes comentários do(s) avaliador(es) do artigo que melhoraram muito a qualidade do trabalho. Destacamos que possíveis erros ou impropriedade são de total responsabilidade dos autores. Agradecemos também o suporte financeiro do Conselho Nacional de Desenvolvimento Científico e Tecnológico (CNPq).

3. Professor titular do curso de economia na Universidade do Estado do Amazonas (UEA).E-mail: <lbsantos@uea.edu.br>. 4. Professor e pesquisador do Departamento de Economia da Universidade Católica de Brasília (UCB).E-mail: <tito@ pos.ucb.br>. 


\title{
LA HIPÓTESIS DE KUZNETS PARA LOS ESTADOS BRASILEÑOS: EVIDENCIA EMPÍRICA DE DATOS EN PANEL PARA EL PERÍODO 1999-2014
}

\begin{abstract}
Este trabajo investigó la relación entre crecimiento económico y desigualdad de ingresos, probando la validez de la hipótesis de Kuznets para las veintisiete unidades federativas de Brasil, a partir de un panel de datos con frecuencia anual, comprendiendo el período 1999-2014. A la metodología se dividió en dos momentos. En el primero, aplicamos la prueba de causalidad de Granger para las variables de interés: índice de Gini, midiendo la desigualdad y la renta domiciliar per cápita media, midiendo el crecimiento económico. En el segundo, estimamos una regresión, estableciendo la desigualdad como variable dependiente en función de la renta per cápita, de la educación, de la inflación y de otras variables de control importantes para explicar esa relación. Los resultados obtenidos señalan con claridad un comportamiento opuesto a la hipótesis de Kuznets. Es decir, la desigualdad, inicialmente disminuye con el aumento de la renta, pero luego, cuando la renta crece de forma más significativa, también asume una trayectoria de crecimiento.
\end{abstract}

Palabras clave: desigualdad y crecimiento; prueba de Granger; hipótesis de Kuznets.

\section{L'HYPOTHÈSE DE KUZNETS POUR LES ÉTATS BRÉSILIENS: PREUVE EMPIRIQUE DES DONNÉES DANS LE PANEL POUR LA PÉRIODE 1999 À 2014}

Ce travail a étudié la relation entre la croissance économique et l'inégalité des revenus, testant la validité de l'hypothèse de Kuznets pour les vingt-sept unités fédératives du Brésil, basée sur un panel de données à fréquence annuelle, comprenant la période de 1999 à 2014. Le méthodologie a été divisée en deux moments. Dans le premier, nous appliquons le test de causalité de Granger aux variables d`intérêt: lıindice de Gini, la mesure de lıinégalité et le revenu moyen par ménage des ménages, mesurant la croissance économique. Dans la seconde, nous estimons une régression, établissant lsinégalité en tant que variable dépendante en fonction du revenu par habitant, de l'éducation, de l'inflation et d'autres variables de contrôle importantes pour expliquer cette relation. Les résultats obtenus indiquent clairement un comportement opposé à l'hypothèse de Kuznets. C'est-à-dire que l'inégalité diminue d'abord avec la hausse des revenus, mais ensuite, lorsque le revenu augmente de manière plus significative, elle prend aussi une trajectoire de croissance.

Mots-clés: inégalité et croissance; test de Granger; hypothèse de Kuznets.

JEL: I2; 13; 01.

\section{INTRODUÇÃO}

O debate em torno da relação entre crescimento econômico versus desigualdade de renda vem despertando interesse em profissionais das mais variadas áreas. Lundberg e Squire (2000) perguntaram se a desigualdade conduz a um baixo crescimento ou se um pífio crescimento é que produz a desigualdade. Piketty (2015) indaga sobre quais são as consequências que a desigualdade traz para o crescimento. Kuznets (1955) também questionou se durante um período de crescimento econômico a desigualdade aumenta ou diminui. O próprio Kuznets formulou uma resposta, que se constituiu no principal fundamento metodológico especializado para quem se propóe a estudar essa relação, a qual ficou conhecida na literatura como a hipótese do U invertido de Kuznets ou simplesmente a curva de Kuznets. 
Segundo essa hipótese, a desigualdade aumenta com o início do crescimento econômico, quando a mão de obra mais especializada migra da área rural em direção à área urbana - do setor menos produtivo para o mais produtivo - e, posteriormente, a desigualdade diminui, quando a maioria dos trabalhadores é absorvida pelo setor mais industrializado. Ao alcançar esse ponto de maturidade, o crescimento se prolonga por vários anos, sustentado pelo aumento da produtividade, e a desigualdade continua a cair.

Há evidências de que o Brasil experimentou um período de significativas quedas nos indicadores de desigualdade a partir de 2001. Conforme Jannuzzi (2016), pode-se constatar esse fato com maior ou menor abrangência temporal, de forma mais irrefletida ou mais crítica, no acervo de publicaçóes institucionais, por exemplo, nas publicaçóes do Ipea, nos relatórios de indicadores sociais do Instituto Brasileiro de Geografia e Estatística (IBGE), nas ediçóes do Programa das Naçóes Unidas para o Desenvolvimento (PNUD), nas publicaçóes da Comissão Econômica para a América Latina e o Caribe (CEPAL), entre outras fontes.

O gráfico 1 evidencia o comportamento da desigualdade por regiáo brasileira, para o período investigado.

\section{GRÁFICO 1}

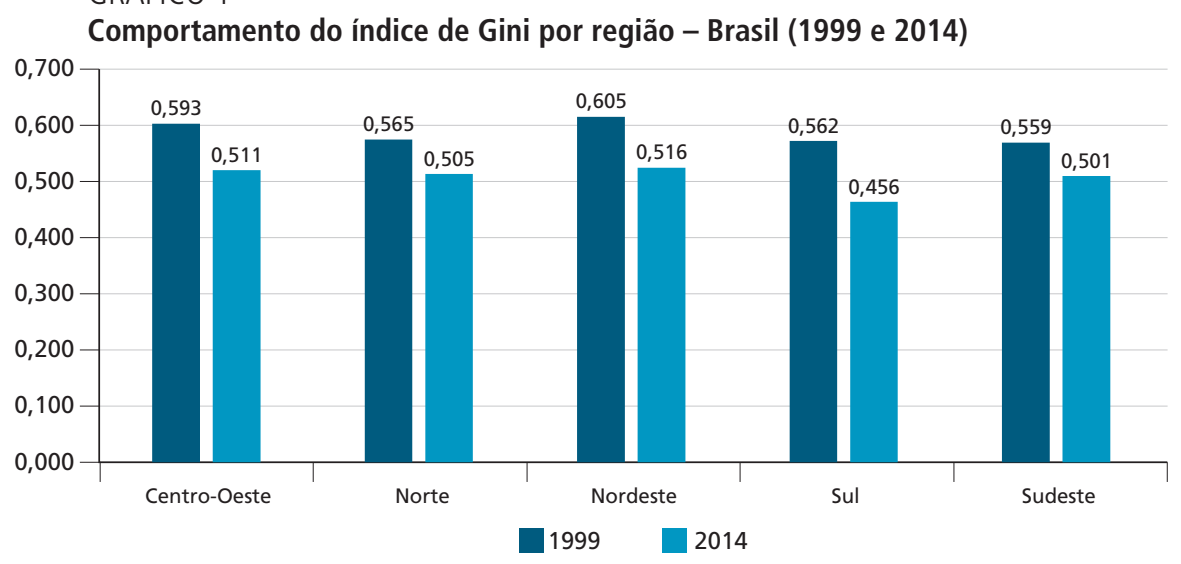

Fonte: Ipeadata. Disponível em: <http://www.ipeadata.gov.br>. Acesso em: 3 out. 2017. Elaboração dos autores.

Comparando os anos extremos da amostra (1999 e 2014), observa-se queda da desigualdade em todas as regióes do país, e de forma tão sistemática que o Brasil chegou a ser internacionalmente apontado como um caso de sucesso econômico, ressalta Mendes (2014). Embora o Nordeste continue a se destacar como a regiáo onde a desigualdade é mais intensa, todos os índices apontam a trajetória de queda da desigualdade em todo país, a qual se estendeu até 2012. Por seu turno, também se acompanha uma elevação do nível de renda em benefício do trabalhador brasileiro, 
principalmente a partir de meados de 2004, com o crescimento do volume das ocupaçôes formais, ${ }^{5}$ saindo de 10,5 mil, em 2004, e ultrapassando a marca de 12,5 mil, em 2007, enquanto as ocupaçóes de natureza informal ${ }^{6}$ permaneceram oscilando em torno de 8,5 mil no mesmo período (Ipea, 2010).

$\mathrm{O}$ fato é que no Brasil o combate à desigualdade por meio de uma distribuição de renda mais justa, observando as carências e as potencialidades regionais, tem sido uma opção de política dos últimos governos que não tem alcançado resultados desejados. As políticas compensatórias, a exemplo do Programa Bolsa Família $(\mathrm{PBF})$, têm sido a estratégia mais utilizada no combate à pobreza e à desigualdade. Por essa via, as regiốes mais carentes de educação, saúde, saneamento e obras de infraestrutura, a exemplo das regióes Norte e Nordeste, mesmo sendo alcançadas por esses programas de assistência, não conseguem emancipar-se economicamente justamente por ainda apresentarem taxas de desigualdade mais elevadas em relaçáo às regiōes mais ricas, a Sul e a Sudeste.

O gráfico 2 mostra o crescimento da renda domiciliar per capita por regiáo para 1999 e 2014.

\section{GRÁFICO 2}

\section{Renda domiciliar per capita média por região - Brasil (1999 e 2014)} (Em R\$)

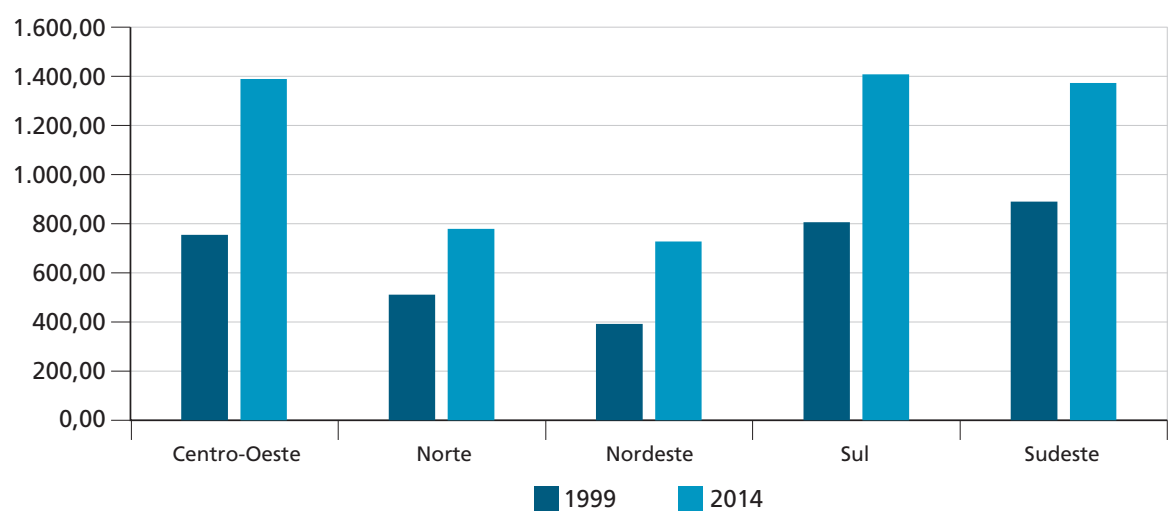

Fonte: Ipeadata. Disponível em: <http://www.ipeadata.gov.br>. Acesso em: 3 out. 2017. Elaboração dos autores.

Nota-se que, proporcionalmente, o gráfico 2 evidencia que a renda cresce menos nas regióes onde a desigualdade é mais intensa (Norte e Nordeste), mas todas as regióes registram crescimento da renda domiciliar per capita. Apesar dessa constatação, um recente diagnóstico realizado pelo PNUD (2015) ainda aponta o

5. 0 estudo inclui na categoria formal os empregados com carteira assinada, militares, servidores públicos e estatutários (Ipea, 2010).

6. Incluem-se nesse grupo os trabalhadores sem carteira assinada, os que trabalham por conta-própria e aqueles sem nenhuma remuneração (Ipea, 2010). 
Brasil como o décimo país mais desigual do mundo e o quarto da América Latina, à frente apenas do Haiti, da Colômbia e do Paraguai. Segundo o estudo, o percentual de desigualdade de renda no Brasil (37\%) é superior à média da América Latina, incluindo os países do Caribe (34,9\%).

Diante dessa realidade, este artigo objetiva entender os mecanismos que estão associados a essa dinâmica e busca encontrar respostas para duas questôes centrais: i) que tipo de relaçáo-causal prevalece entre crescimento econômico e desigualdade de renda? e ii) a hipótese da curva do U invertido de Kuznets é válida para explicar o comportamento da desigualdade de renda da economia brasileira?

Ao investigar dados dos Estados Unidos, da Alemanha e da Inglaterra, Kuznets concluiu que o ritmo do desenvolvimento de uma economia deve seguir o compasso dos processos tecnológicos que, aos poucos, vão se incorporando em cada segmento. Essas transformaçóes devem ser permanentemente acompanhadas de mudanças institucionais que permitam a transferência de recursos entre os diferentes setores da indústria e da economia como um todo. Por essa lógica, o crescimento econômico capaz de promover o bem-estar e de combater a desigualdade não pode advir apenas da manipulação das taxas de juros e da quantidade de investimentos em atividades produtivas isoladas sem nenhum planejamento estratégico, mas do aumento da eficiência na utilização dos recursos e das mudanças qualitativas induzidas pelas mudanças quantitativas, nos mais variados setores da economia.

Desde a publicação dessa teoria, diversos estudos buscam analisar essa relação a partir de diferentes estratégias metodológicas, sendo a maioria delas fundadas em modelos paramétricos. Para Figueiredo, Jacinto e Silva Junior (2011), esse tipo de abordagem ganhou a preferência dos estudos, tanto em nível nacional quanto internacional, pela simplicidade de sua forma funcional. Barro (2000), Thornton (2001), Bagolin, Gabe e Ribeiro (2004), Jacinto e Tejada (2004) e Salvato et al. (2006) são exemplos de estudos que adotaram essa abordagem.

De forma resumida, a estratégia utilizada é basicamente a seguinte: definem-se uma medida de desigualdade, em geral, o índice de Gini ou de Theil, e uma medida de crescimento ou de desenvolvimento, que pode ser a renda domiciliar per capita ou o produto interno bruto (PIB) per capita, e fixa-se a condição de concavidade da curva, parâmetro necessário para validar a hipótese de Kuznets. Em seguida, são realizados os testes e, a partir das formas matemáticas estabelecidas e da robustez dos resultados, conclui-se pela validade ou não da hipótese de Kuznets.

Barros e Gomes (2008) também adotaram essa mesma lógica para testar a hipótese de Kuznets para os municípios brasileiros. Ao final da análise, ao encontrar resultados ambíguos, validando a hipótese de Kuznets para algumas especificaçóes e rejeitando-a quando se fez uso de um modelo mais geral, os autores admitem que a ausência de outras variáveis explicativas possa ter inviabilizado a obtenção de resultados mais claros e sugerem que, em trabalhos futuros, se adote essa estratégia. 
$\mathrm{Na}$ visão Mendes (2014), é inadequado explicar a desigualdade, sobretudo a brasileira, sem levar em conta fatores importantes que estão na vanguarda do problema, aparecendo como causas ou como consequências, tais como a renda per capita, a educação, o acesso a serviços públicos básicos, o crescimento econômico, o grau de informalidade, a inflação, entre outros.

Considerando essas evidências, esta pesquisa testa a validade da curva de Kuznets a partir de um painel de dados com frequência anual para os estados brasileiros e o Distrito Federal, compreendendo o período 1999-2014. Inicialmente, aplica-se o teste de causalidade de Granger para as principais variáveis de interesse: o índice de Gini, medindo a desigualdade, e a renda domiciliar per capita média, medindo o crescimento econômico. Em seguida, são feitas duas estimativas estabelecendo a desigualdade como função de oito variáveis de controle: renda domiciliar per capita, educação, informalidade, mortalidade infantil, Índice de Preço ao Consumidor Amplo (IPCA), ${ }^{7}$ inflação, pobreza e desemprego.

Os resultados dos testes de causalidade, tanto com os valores em nível quanto com os valores em diferença, sinalizam uma causalidade que parte do crescimento para a desigualdade, no sentido de Granger. Os resultados das estimativas não apenas rejeitam a hipótese de Kuznets como mostram um comportamento diferente. Os sinais opostos dos coeficientes das variáveis renda (negativo) e renda ao quadrado (positivo) indicam que, inicialmente, a desigualdade cai com o aumento da renda, mas, em seguida, quando a renda se evidencia, a desigualdade também cresce, revelando um comportamento em total desacordo com a hipótese de Kuznets.

Nesse contexto, a relevância dessa investigação está na possibilidade de se contribuir com a literatura sob dois aspectos. Primeiramente, ampliando a compreensão da relação que se estabelece na economia brasileira entre crescimento econômico e desigualdade de renda, a partir do teste de causalidade de Granger, que, segundo Santos, Jacinto e Tejada (2012), é uma técnica relativamente pouco usada para dados em painel; e, em segundo lugar, obtendo resultados mais evidentes sobre a aplicação da hipótese de Kuznets para as Unidades da Federação (UFs) brasileiras, incorporando ao modelo econométrico variáveis importantes, como desemprego, inflaçáo, pobreza, informalidade, entre outras. A ausência desses fatores pode inviabilizar a obtenção de resultados mais claros, conforme destaca Barros e Gomes (2008).

Ao aprofundar a discussão em torno desses tópicos, espera-se também ampliar a compreensão sobre os fatores que afetam o comportamento da distribuição de renda na economia brasileira e sobre a relação que se estabelece entre o crescimento econômico e a desigualdade de renda. A complexidade da economia brasileira, as imperfeiçóes do mercado, a extensão territorial do país e as profundas diferenças regionais fazem da desigualdade um problema crônico e persistente, e, para combatê-la efetivamente, é necessário entender os mecanismos que estão conexos à sua dinâmica.

7. O IPCA foi incorporado na regressão na forma de primeira diferença do Índice Nacional de Preços ao Consumidor: D(INPC). 
Com esse propósito, e buscando preencher algumas lacunas reclamadas pela literatura, este trabalho está estruturado em mais quatro seções, além desta introdução. A seção 2 faz uma revisão de literatura a respeito do tema. A seção 3 expóe os procedimentos metodológicos utilizados. A seção 4 apresenta e discute os resultados. E, por fim, a seção 5 traz as consideraçóes finais.

\section{REVISÃO DE LITERATURA}

A desigualdade de renda tem se revelado um tema marcante tanto no meio político quanto no ambiente acadêmico. Essa relevância, segundo Linhares et al. (2012), se dá, basicamente, por duas razôes: a primeira está na evidência de sua persistência histórica. Isto é, os padrôes de desigualdade que se constituíram com a formação da sociedade não são facilmente alterados. Mesmo diante de políticas sociais de redistribuição de renda, a desigualdade persiste e se mantém quase inalterada. A segunda razão está em uma gama de problemas decorrentes da própria desigualdade, como pobreza, criminalidade, baixa escolaridade, desemprego e várias outras situaçóes que separam o homem de sua cidadania, formando a imensa classe dos menos favorecidos. O Brasil é um típico exemplo dessa realidade.

Santos, Miranda e Moreira (2012) explicam que o problema das desigualdades sociais no Brasil é gravíssimo e não se trata de um fenômeno recente. Ao contrário, surgiu e foi se agravando em meio ao processo de formação e de consolidação do país. Transparece como um problema insolúvel, pois parece estar inscrito na nossa própria natureza. Conforme Gründler e Scheuermeyer (2014), quando maior o nível de desigualdade de certa sociedade, maiores os empecilhos ao crescimento. Nessas condições, a desigualdade pode até esmorecer durante um período, mas o seu retorno a níveis alarmantes deve ser esperado. Ostry, Berg e Tsangarides (2014) argumentam que nas regióes mais pobres, por exemplo, o aumento da renda parece não ter qualquer efeito sobre sua distribuição. A desigualdade pode ser prejudicial ao crescimento, pois ela gera instabilidade política e econômica, reduz o investimento e impede o consenso social necessário para ajustar os choques e sustentar o crescimento.

O Brasil experimentou um período de significativas quedas nos indicadores de desigualdade ao longo dos primeiros anos do século XXI, o que o levou a ser internacionalmente apontado como um bom exemplo de sucesso econômico, como país que sabe combater com eficácia a pobreza e a desigualdade, ${ }^{8}$ ressalta Mendes (2014). Apesar dessa evidência, o Brasil continua no topo do ranking mundial das injustiças sociais. Perante essa realidade, o desafio de conciliar crescimento econômico com um menor grau de desigualdade é sempre uma questáo atual, que merece destaque e que motiva a busca de respostas; afinal, para combater a desigualdade, é preciso conhecer os elementos que estấo conexos à sua dinâmica e à sua reprodução. 
Um dos trabalhos mais destacado na literatura que discute a relação entre desigualdade e crescimento econômico é o artigo de Kuznets (1955), que se perguntou: a desigualdade aumenta ou diminui no decorrer de um período de crescimento de um país? Investigando dados dos Estados Unidos, da Alemanha e da Inglaterra, o autor concluiu que, em estágios iniciais do desenvolvimento, há uma relação positiva entre crescimento e desigualdade, em função dos processos migratórios da mão de obra mais habilidosa de setores menos dinâmicos - tradicionais e com baixo retorno - para setores mais dinâmicos, com alto retorno, gerando uma crescente desigualdade na distribuição de renda entre os indivíduos.

Esse movimento migratório, alinhado à utilização de máquinas e equipamentos, gera ganhos de produtividade, aumentando a diferença de renda entre os dois grupos. Essa relaçáo só é modificada quando a economia alcança determinado patamar de maturidade. A partir daí, há um processo gradual de homogeneização na produtividade dessa mão de obra, resultando em uma redução da desigualdade de renda, na medida em que a economia continua crescendo. A partir desse ponto, a desigualdade toma uma trajetória de queda, ganhando o formato de um $\mathrm{U}$ invertido, que ficou conhecido como a hipótese de Kuznets.

Desde a publicação dessa teoria, grande parte dos trabalhos que se propóem a investigar a relação entre crescimento e desigualdade toma como fundamento a hipótese de Kuznets, buscando testar a sua validação para os seus objetos de análise. Segundo Barros e Gomes (2008), a abordagem preferida nesse campo é o uso de modelos paramétricos. A forma mais simples consiste na estimação do modelo: $I=\alpha_{0}+\alpha_{1} D+\alpha_{2} D^{2}+\varepsilon_{t}$, sendo $d^{2} \mathrm{I} / d D^{2}=2 \alpha_{2}$, em que: $I$ é uma medida de desigualdade e $D$ uma medida de desenvolvimento econômico. A condição para se encontrar uma curva côncava é $\alpha<0$.

Vários autores fizeram uso dessa abordagem, a exemplo de Thornton (2001), que fez essa análise tomando como objeto de estudo um conjunto de 96 países, a partir das variáveis: Gini, quintis de renda e PIB per capita, ao longo do período pós-guerra. Segundo o autor, os resultados a favor da hipótese de Kuznets não são claros, em razão das dificuldades de comparabilidade entre os dados dos vários países.

Nessa mesma linha, utilizando dados de séries temporais para a economia americana, Hsing e Smith (1994) não rejeitam a hipótese de Kuznets. Mushinski (2001), a partir de um polinômio do quarto grau, trabalhando com os dados do censo decenal de 212 regióes dos Estados Unidos e admitindo a renda per capita como medida de desenvolvimento e o índice de Gini como medida da desigualdade, chegou a resultados favoráveis à hipótese de Kuznets.

Huang et al. (2007), por meio de uma regressão, testam a validade da hipótese de Kuznets, fazendo uso de dados cross-section de 75 países, trabalhando a renda com base em diferentes quantis. Os autores acharam robustos resultados em favor 
da hipótese de Kuznets. Barro (2000), ao estudar o comportamento da relação entre crescimento e desigualdade para vários países, encontrou uma baixa relação entre ambas. Em outros termos, a hipótese de Kuznets é válida dependendo do nível de renda.

Em âmbito nacional, os estudos têm sistemática semelhante à adotada em trabalhos internacionais. Figueiredo, Silva Junior e Jacinto (2011) testaram a curva de Kuznets para os municípios brasileiros em 1991 e 2000. Considerando a forma reduzida sugerida por Ahluwalia $(1976)^{9}$ - na qual a desigualdade é explicada por um polinômio do segundo grau da renda per capita, com o índice de Gini medindo o grau de desigualdade e a renda per capita usada como proxy para o nível de desenvolvimento econômico -, após vários testes de especificação, os autores notaram que os resultados sugerem a validade da hipótese de Kuznets, quando se fez uso das estimaçóes não paramétricas. Nos demais testes, os resultados apontaram para a inconsistência da estrutura quantílica linear para o conjunto de dados do estudo.

Bêrni, Marquetti e Kloeckmer (2002) fizeram a análise considerando setores distintos da economia gaúcha, utilizando o método não paramétrico de regressão local. Os autores sugerem cautelosa aceitação da curva de Kuznets e admitem a necessidade de se utilizar métodos mais sofisticados e estratégias diferenciadas para alcançar resultados mais claros.

Segundo Glaeser (2005), a trajetória que a curva de Kuznets toma durante um período de crescimento não é fruto apenas de fatores econômicos, mas também de fatores políticos. Com o avanço da industrialização, surge também um grau maior de educação e uma maior capacidade de organização popular, o que pode desencadear sobre o governo pressôes por maior redistribuição de renda.

Barros e Gomes (2008) também investigaram a hipótese da curva de Kuznets para os 5.507 municípios brasileiros em 1999 e 2001. Com a desigualdade medida pelos índices de Gini e Theil e as medidas de desenvolvimento representadas pela renda per capita e fração da população urbana, os resultados foram ambíguos: algumas especificações rejeitaram a hipótese de Kuznets e outras não. Entretanto, todos os modelos apresentaram um poder explicativo muito fraco. Os autores sugerem que estudos futuros incluam outras variáveis explicativas, as quais possam gerar uma melhor compreensão da relação crescimento versus desigualdade.

Linhares et al. (2012), seguindo a mesma lógica de Barros e Gomes (2008), buscaram verificar a validade da hipótese de Kuznets para os municípios brasileiros em 1991, 2000 e 2010, por meio da aplicação de dados em painel, utilizando informaçóes do Atlas do Desenvolvimento Humano do Brasil (PNUD, 2013), os

9. Ahluwalia (1976) propôs uma forma mais geral para a modelagem da curva de Kuznets, com o intuito de captar as influências e mudanças estruturais presentes nos modelos elaborados para testar a hipótese de Kuznets. 
coeficientes de Gini e L de Theil como medidas de desigualdade e a renda per capita como medida de crescimento. Os resultados também foram ambíguos: a hipótese de Kuznets é aceita sob algumas particularizaçóes, mas é rejeitada sob a análise de um modelo mais geral.

Como se pode percebe, os exames entre crescimento econômico e desigualdade, em sua maioria, fazem uso de equaçóes polinomiais de segundo ou de terceiro grau, a partir de modelos funcionais que permitem validar a curva de Kuznets, privilegiando o uso das variáveis principais, crescimento e desigualdade, e tomam como fundamentos os modelos prescritos na literatura, alguns aqui já mencionados.

Nota-se que os resultados dos estudos têm se mostrados contraditórios e podem ser sistematizados em três grupos: $i$ ) aqueles favoráveis à hipótese do U invertido; ii) aqueles cautelosos em suas conclusões, em função do baixo poder explicativo de seus estimadores e, por isso, sugerem novos estudos incluindo outras variáveis explicativas e outras estratégias metodológicas para o tratamento da questão; e iii) aqueles cujos resultados rejeitam a hipótese de Kuznets.

A pesquisa em tela busca contribuir com essa discussão, testando a validade da hipótese de Kuznets para o Brasil, mas começa investigando o efeito causalidade entre crescimento econômico e desigualdade de renda, por meio do teste de causalidade de Granger, empregando um painel de dados com frequência anual para os 26 estados da Federação e o Distrito Federal, considerando o período 1999-2014.

Santos, Jacinto e Tejada (2012) aplicaram essa metodologia para analisar a relação de causalidade entre renda e saúde para os estados do Brasil. Para tanto, os autores fizeram uso de três testes de causalidade propostos, respectivamente, por Holtz-Eakin, Newey e Rosen (1988), Granger e Huang (1997) e Hurlin (2005) e Hurlin et al. (2007), para o período compreendido entre 1981-2007. Considerando a variável renda domiciliar per capita como representante da renda e a taxa de mortalidade na infância como variável representante da saúde, os resultados da análise apontam que, no Brasil, as evidências são mais claras para causalidade no sentido da saúde para a renda. Sobre o uso dessa metodologia os autores evidenciam que:

A sua aplicação aos modelos de séries de tempo é extensa, aos modelos que utilizam dados em painel ainda são relativamente recentes. Entre as vantagens da utilizaçáo de dados em painel, pode ser destacado o maior número de observaçóes, que aumenta os graus de liberdade e reduz o grau de colinearidade entre variáveis explicativas e, consequentemente, melhora a eficiência do parâmetro estimado (Santos, Jacinto e Tejada, 2012, p. 238).

Assim, o teste de causalidade proposto neste estudo visa superar as limitaçóes do uso de simples correlaçôes entre variáveis, ao considerar que a relação entre crescimento e desigualdade não pode ser explicada apenas por si mesma. É preciso considerar outros fatores, como educação, pobreza, desemprego, informalidade, 
inflação etc., determinantes na estrutura econômica do crescimento e da desigualdade, lembrando também que a ausência desses fatores na análise pode comprometer a robustez dos resultados de alguns estudos, como tem sido evidenciado na literatura.

\section{PROCEDIMENTOS METODOLÓGICOS}

A proposta deste artigo, que também faz uso de um modelo paramétrico, é responder a algumas demandas presentes na literatura com relação ao objeto de estudo. O objetivo é testar a validação da curva de Kuznets para os estados brasileiros, por meio de duas estratégias metodológicas complementares: a primeira consiste no teste de causalidade de Granger entre as principais variáveis de interesse, o índice de Gini, medindo a desigualdade de renda, tomada como variável dependente, e a renda domiciliar per capita média, como proxy para o crescimento econômico, tomada como variável independente, a partir de um painel de dados para as 27 UFs do Brasil, no período 1999-2014.

$\mathrm{O}$ teste de causalidade que ficou mais popularizado na literatura deve-se ao econometrista Clive Granger, o qual propóe que o futuro não pode causar o passado nem o presente. Isso significa que, se o evento A ocorre depois do evento $\mathrm{B}$, A náo pode causar $\mathrm{B}$. Ao passo que, se $\mathrm{A}$ ocorreu antes de $\mathrm{B}$, isso não evidência que $A$, necessariamente, cause $B$.

O teste afirma que as informações necessárias para se identificar a predição de uma variável sobre a outra estão contidas apenas nas próprias séries em análise. Essa é a essência do teste de causalidade de Granger, que não se propõe a identificar uma relação de causalidade no seu sentido de endogeneidade. Assim, para esse teste, segue-se o modelo proposto por Sims (1980). A estimação se dá com base na seguinte equação:

$$
Y_{i t}=A_{0} X_{i t}+A_{1} X_{i, t-1}+\ldots+A_{n} X_{i, t-n}+\varepsilon_{t},
$$

em que $Y_{i t}$ é a representação de uma medida de desigualdade do estado $i$ no ano $t$; $A_{0}$ e o intercepto, $A_{1}$ e $A_{n}$ são os coeficientes resultados da regressão; $X_{i, t-1, t-n}$ são as variáveis defasadas; e $\varepsilon_{t}$ é o termo aleatório do erro.

A segunda estratégia metodológica nasce da compreensão de que nem o crescimento nem a desigualdade podem ser explicados com base apenas em si mesmos; desse modo, esta análise consiste na estimação de um modelo econométrico, no qual a desigualdade é tomada como variável dependente a ser explicada por algumas variáveis de controle, conforme a equação 2 .

$$
\begin{aligned}
& \text { Desig }_{i t}=\alpha+B_{0} \text { Renda }_{i t}+B_{1}\left(\text { Renda }_{i t}{ }^{2}+B_{2} \text { ipca }_{i t}+B_{3} \text { Npobres }_{i t}\right. \\
& +B_{4} \text { Popdesoc }_{i t}+B_{5} \text { TXmorinf }_{i t}+B_{6} \text { Educação }_{i t}+B_{7} \text { Ginformalidad }_{i t} .
\end{aligned}
$$


O quadro 1 descreve as variáveis da equação 2.

QUADRO 1

Descrição das variáveis

\begin{tabular}{|c|c|}
\hline Variável (nomenclatura) & Descrição \\
\hline Gini (Desig) & $\begin{array}{l}\text { Mede o grau de desigualdade na distribuição da renda domiciliar per capita entre os } \\
\text { indivíduos. Seu valor pode variar teoricamente desde } 0 \text {, quando não há desigualdade, } \\
\text { até } 1 \text {, quando a desigualdade é máxima. }\end{array}$ \\
\hline $\begin{array}{l}\text { Renda domiciliar per capita } \\
\text { (Renda) }\end{array}$ & Renda domiciliar per capita (média): em reais ( $R \$$ ) de outubro de 2014. \\
\hline Educação (Educação) & Média de anos de estudos das pessoas com idade mínima de 25 anos de idade. \\
\hline $\begin{array}{l}\text { Grau de informalidade } \\
\text { (Ginformalidad) }\end{array}$ & $\begin{array}{l}\text { Razão: (empregados sem carteira + trabalhadores por conta-própria) / (trabalhadores } \\
\text { protegidos + empregados sem carteira + trabalhadores por conta-própria). }\end{array}$ \\
\hline Número de pobres (Npobres) & $\begin{array}{l}\text { Número de pessoas em domicílios com renda domiciliar per capita inferior à linha de } \\
\text { pobreza, equivalente a meio salário mínimo. }\end{array}$ \\
\hline $\begin{array}{l}\text { Taxa de mortalidade infantil } \\
\text { (TXmorinf) }\end{array}$ & Taxa de mortalidade infantil: por 1 mil nascidos vivos (óbitos). \\
\hline IPCA & IPCA: em porcentagem ao ano (a.a.). \\
\hline
\end{tabular}

Fontes: IBGE e Ipeadata (disponíveis em: <https://bit.ly/2Q5ChPB > e <http://www.ipeadata.gov.br>). Acessos em: 3 out. 2017.

Para o caso de dados em painel, a estimativa pode ser realizada com base nos modelos de efeitos fixos ou aleatórios. Daí decorre a importância do teste de Hausman. Nos modelos de efeitos fixos, a estimação é feita assumindo que a heterogeneidade dos indivíduos se capta na parte constante, que é diferente de indivíduo para indivíduo, tal que:

$$
Y_{i t}=\alpha_{i}+b X_{i t}+\ldots+u_{i t},
$$

em que há heterogeneidade na parte constante e homogeneidade nas inclinaçôes. A parte constante $\alpha_{i}$ é diferente para cada indivíduo (cada UF), captando diferenças invariantes no tempo, a exemplo da dimensão dos países, de recursos naturais e de outras características que não variam no curto prazo.

Nos modelos de efeitos aleatórios, a estimação é feita introduzindo a heterogeneidade dos indivíduos no termo de erro, tal que:

$$
Y_{i t}=\alpha_{i}+b X_{i t}+\ldots+\left(\eta_{i}+u_{i t}\right)
$$

em que $\alpha_{i}=\alpha+\eta_{i}$ e $\eta_{i}$ representa o efeito aleatório individual não observável. 
Os modelos com efeitos aleatórios consideram a constante não como um parâmetro fixo, mas, sim, como um parâmetro aleatório não observável. Os modelos com efeitos fixos consideram que as diferenças dos indivíduos (países, regiōes, estados etc.) captam-se na parte constante. Os modelos com efeitos aleatórios consideram que essas diferenças são captadas no termo de erro. Essas são as principais diferenças entre os dois modelos em painel.

Utiliza-se o teste de Hausman para escolher qual modelo é o mais adequado, fixo ou aleatório. A hipótese nula do teste assegura que o modelo de efeito aleatório é o mais adequado. Se a hipótese nula não for aceita, ou seja, se for rejeitada, então o modelo de efeito fixo será o mais apropriado. No caso em tela, os testes apontam que o modelo de efeito fixo é o mais adequado.

A seguir, nas tabelas 1 e 2, expóem-se, respectivamente, as estatísticas descritivas e a matriz de correlação referentes às séries utilizadas no modelo econométrico para o período investigado.

TABELA 1

Estatísticas descritivas - painel de dados (1999-2014)

\begin{tabular}{lrrrrrrr}
\hline & \multicolumn{1}{c}{ Gini } & \multicolumn{1}{c}{ Renda } & \multicolumn{1}{c}{ (Renda) } & Npobres & Educação & Ginformalidad & TXmortinf \\
\hline Média & 0,580581 & 663,6764 & 447654,8 & 17164069,0 & 6,190697 & 60,05153 & 22,63250 \\
Mediana & 0,580797 & 660,1933 & 435881,1 & 1124513,0 & 6,229973 & 60,81224 & 21,15000 \\
Máximo & 0,623301 & 791,6796 & 626756,6 & 8236135,0 & 6,971600 & 90,32019 & 63,70000 \\
Mínimo & 0,524910 & 495,2826 & 245304,9 & 61553,0 & 5,192545 & 33,84645 & 9,600000 \\
Desvio-padrão & 0,030496 & 84,88295 & 109831,1 & 1709425,0 & 0,502329 & 12,18884 & 8,900597 \\
Observações & 432 & 432 & 432 & 432 & 432 & 432 & 432 \\
\hline
\end{tabular}

Fonte: Ipeadata. Disponível em: <http://www.ipeadata.gov.br>. Acesso em: 3 out. 2017.

Elaboração dos autores.

A tabela 2 mostra a correlaçáo entre todas as variáveis.

TABELA 2

Matriz de correlação - painel de dados (1999-2014)

\begin{tabular}{lcccccccc}
\hline & Gini & Renda & (Renda) $^{2}$ & Educação & Ginformalidad & IPCA & Npobres & TXmorinf \\
\hline Gini & 1,000000 & 0,046832 & 0,062799 & $-0,427030$ & 0,291501 & 0,296473 & 0,186345 & 0,299728 \\
Renda & 0,046832 & 1,000000 & 0,997107 & 0,781718 & $-0,111842$ & 0,110131 & $-0,115903$ & $-0,145914$ \\
(Renda) $^{2}$ & 0,062799 & 0,997107 & 1,000000 & 0,764950 & $-0,109758$ & 0,112198 & $-0,114222$ & $-0,148452$ \\
Educação & $-0,427030$ & 0,781718 & 0,764950 & 1,000000 & $-0,266906$ & $-0,156357$ & $-0,208536$ & $-0,326900$ \\
Ginformalidad & 0,291501 & $-0,111842$ & $-0,109758$ & $-0,266906$ & 1,000000 & 0,187122 & 0,137960 & 0,693350 \\
IPCA & 0,296473 & 0,110131 & 0,112198 & $-0,156357$ & 0,187122 & 1,000000 & 0,121040 & 0,223787 \\
Npobres & 0,186345 & $-0,115903$ & $-0,114222$ & $-0,208536$ & 0,137960 & 0,121040 & 1,000000 & 0,189461 \\
TXmortinf & 0,299728 & $-0,145914$ & $-0,148452$ & $-0,326900$ & 0,693350 & 0,223787 & 0,189461 & 1,000000 \\
\hline
\end{tabular}

Fonte: Ipeadata. Disponível em: <http://www.ipeadata.gov.br>. Acesso em: 3 out. 2017.

Elaboração dos autores. 
A literatura considera que, quando há forte correlação entre algumas variáveis explicativas, pode-se incorrer em problemas de endogeneidade, que podem ser resolvidos como o uso de variáveis instrumentais. De fato, observa-se, como esperado, uma forte correlação de 0,997 entre Renda e (Renda) ${ }^{2}$. Entretanto, para testar a proposição de Kuznets, é inevitável a utilização simultânea de Renda e $(\text { Renda })^{2}$. Nota-se também uma correlação alta entre Renda e Educação de 0,78, o que também é esperado. Dessa forma, estima-se um painel com base em estimativas via método de estimação de mínimos quadrados generalizados factíveis (FGLS, do inglês feasible generalized last squares) considerando-se que o termo do erro não é independente e identicamente distribuído. Esse método corrige possíveis problemas de autocorrelação, correlação entre painéis e heterocedasticidade. Além disso, utiliza-se painel dinâmico com variáveis instrumentais em primeira diferença para mitigar possíveis problemas de endogeneidade (Wooldridge, 2002).

Ademais, vale destacar que, segundo Baltagi (2013), ao combinar séries temporais com dados transversais, os dados em painel fornecem mais dados informativos, mais variabilidade e menos colinearidade entre variáveis, mais graus de liberdade e mais eficiência. Eles também fornecem controle da heterogeneidade individual, ao contrário da estrutura de dados de séries temporais, que sofre de multicolinearidade.

O teste de Breusch e Pagan é utilizado no modelo de painel para testar a presença de heteroscedasticidade. Uma vez que a hipótese nula de variância constante não é aceita, utiliza-se o erro-padrão robusto para corrigir os problemas de heteroscedasticidade em dados de painel. Pode-se verificar que nas estimativas das tabelas 8 e 9, de painel com feitos fixos, utiliza-se o erro robusto como procedimento para mitigar tais problemas.

Utiliza-se também estimativa pelo método painel FGLS com dummies para regióes e por ano para o período 1999-2014, para fins de correção para possíveis problemas de heteroscedasticidade e autocorrelação, conforme as tabelas A.2 e A.3 (apêndice A). A tabela A.1 do apêndice A mostra testes de raiz unitária para dados em painel de Levin-Lin-Chu. Os resultados indicam que as séries são estacionárias.

\section{APRESENTAÇÃO E DISCUSSÃO DOS RESULTADOS}

A primeira parte da análise dos resultados consiste na aplicação do teste de causalidade de Granger. A análise desse teste inicia-se pela estimação de um modelo vetorial autorregressivo (VAR), envolvendo as séries em questão. Como o teste de causalidade é um teste de precedência temporal, o número de defasagens a ser incluído assume um grau de relativa importância. Normalmente, esse número é obtido observando os critérios de informação de estimador de máxima verossimilhança (LR), o critério de informação de Akaike (AIC), o critério de informação de 
Schwarz (SC), o critério de informação de Hannan-Quinn (HQ) e o erro final de predição (FPE), que são naturalmente exibidos ao se realizar a estimação do VAR. Como não existe um consenso na literatura identificando qual desses estimadores é o mais adequado, a prática adotada é usar o número de defasagens (lags) apontado pelo maior número de critérios.

A causalidade de Granger da variável $x$ para a variável $y$ é avaliada testando a hipótese nula de que todos os coeficientes da variável $x$, em todas as defasagens, são, simultaneamente, estatisticamente iguais a zero, na equação em que $y$ é a variável independente. Caso a hipótese nula seja rejeitada, conclui-se que a variável $x$ causa a variável $y$, no sentido de Granger.

As tabelas 3 e 4 constam, respectivamente, dos resultados do modelo VAR e do teste de causalidade para os valores em nível.

TABELA 3

Resultados do modelo VAR

\begin{tabular}{lcccccc}
\hline Lag & LogL & \multicolumn{1}{c}{$\mathrm{LR}^{1}$} & FPE & AIC & SC & \multicolumn{1}{c}{ HQ $^{2}$} \\
\hline 0 & $-1154,349$ & - & 153,1140 & 10,70694 & 10,73819 & 10,71956 \\
1 & $-835,8860$ & 628,0803 & 8,326887 & 7,795240 & 7,888998 & 7,833119 \\
2 & $-792,4070$ & 84,94505 & 5,777416 & 7,429694 & 7,585957 & 7,492825 \\
3 & $-777,6184$ & 28,61864 & 5,228326 & 7,329800 & 7,548568 & 7,418183 \\
4 & $-775,7979$ & 3,489193 & 5,335184 & 7,349981 & 7,631254 & 7,463616 \\
5 & $-741,4296$ & 65,23624 & 4,027777 & 7,068792 & $7,412571^{*}$ & $7,207680^{*}$ \\
6 & $-735,7137$ & 10,74383 & 3,964744 & 7,052904 & 7,459188 & 7,217044 \\
7 & $-734,9134$ & 1,489347 & 4,084606 & 7,082532 & 7,551320 & 7,271923 \\
8 & $-722,8947$ & $22,14554^{*}$ & $3,793097^{*}$ & $7,008284^{*}$ & 7,539578 & 7,222928 \\
\hline
\end{tabular}

Fonte: Ipeadata. Disponível em: <http://www.ipeadata.gov.br>. Acesso em: 3 out. 2017.

Elaboração dos autores.

Notas: ${ }^{1} \mathrm{LR}=$ cada teste ao nível de $5 \%$.

${ }^{2} \mathrm{HQ}=$ observações inclusas 216 .

Obs.: * Indica a ordem das defasagens pelo critério de seleção.

TABELA 4

Resultados do primeiro teste de causalidade com valores em nível

\begin{tabular}{lccc}
\hline Hipótese nula $(\mathrm{H} 0)$ & Observações & Estatística F & Probabilidade \\
\hline Renda does not Granger Cause Gini & 216 & 3,24510 & 0,0017 \\
Gini does not Granger Cause Renda & - & 1,13419 & 0,3418 \\
\hline
\end{tabular}

Fonte: Ipeadata. Disponivel em: <http://www.ipeadata.gov.br>. Acesso em: 3 out. 2017.

Elaboração dos autores.

A tabela 3 mostra que com 216 observaçóes percebe-se a indicação de 8 lags como o número ótimo de defasagens apontados pelos critérios LR, FPE e AIC, para as variáveis de interesse Gini e Renda, compreendendo o período 1999-2014. Isto significa que o teste de causalidade de Granger foi estimado com 8 lags. $\mathrm{Na}$ tabela 4, a primeira hipótese, HO: Renda does not Granger Cause Gini, é rejeitada, 
uma vez que a probabilidade é inferior a 0,05 . Dessa forma, não se aceita a hipótese nula de que a Renda não precede temporalmente a variável Gini. Por consequência, Renda causa ou precede temporalmente Gini. Em outras palavras, há uma relação de causalidade partindo da variável Renda para a variável Gini. A segunda hipótese, HO: Gini does not Granger Cause Renda, não é rejeitada, ela apresenta uma probabilidade de 0,3418. Assim, não se rejeita a hipótese nula de que Gini não precede temporalmente a variável Renda, ou seja, Gini não causa ou náo precede temporalmente Renda. Em outras palavras, não há uma relação de causalidade partindo da variável Gini para a variável Renda. Logo, conclui-se que há uma causalidade que parte da renda para a desigualdade, no sentido de Granger. Esse resultado está de acordo com a curva de Kuznets, no sentido de que mostra o efeito do crescimento sobre a desigualdade, embora o autor não tenha realizado um teste de causalidade entre as duas variáveis. Essa é uma das contribuiçóes deste trabalho.

As tabelas 5 e 6 expóem os resultados do modelo VAR e do segundo teste de causalidade, agora com os valores em diferença.

TABELA 5

Resultados do VAR com valores em diferença

\begin{tabular}{lcccccc}
\hline Lag & LogL & LR & FPE & AIC & SC & HQ $^{2}$ \\
\hline 0 & $-754,6139$ & - & 10,28558 & 8,006496 & 8,040801 & 8,020394 \\
1 & $-708,0357$ & 91,67782 & 6,554712 & 7,555933 & 7,658846 & 7,597625 \\
2 & $-695,7473$ & 23,92651 & 6,004422 & 7,468226 & 7,639747 & 7,537713 \\
3 & $-695,3850$ & 0,697792 & 6,240332 & 7,506720 & 7,746849 & 7,604002 \\
4 & $-667,4819$ & 53,14876 & 4,846064 & 7,253777 & $7,562515^{*}$ & 7,378854 \\
5 & $-663,8517$ & 6,837922 & 4,865643 & 7,257690 & 7,635036 & 7,410562 \\
6 & $-661,0690$ & 5,182578 & 4,929572 & 7,270571 & 7,716526 & 7,451238 \\
7 & $-642,7946$ & $33,64814^{*}$ & $4,239452^{*}$ & $7,119519^{*}$ & 7,634082 & $7,327981^{*}$ \\
8 & $-639,0826$ & 6,756079 & 4,253697 & 7,122568 & 7,705739 & 7,358824 \\
\hline
\end{tabular}

Fonte: Ipeadata. Disponivel em: <http://www.ipeadata.gov.br>. Acesso em: 3 out. 2017.

Elaboração dos autores.

Notas: ${ }^{1} \mathrm{LR}=$ cada teste ao nível de $5 \%$.

${ }^{2} \mathrm{HQ}=$ observações inclusas 189.

Obs.: * Indica a ordem das defasagens pelo critério de seleção.

TABELA 6

Resultados do segundo teste de causalidade com valores em diferença

\begin{tabular}{lccc}
\hline Hipótese nula (HO) & Observações & Estatística F & Probabilidade \\
\hline D(Renda) does not Granger Cause D(Gini) & 189 & 3,66131 & 0,0010 \\
D(Gini) does not Granger Cause D(Renda) & - & 1,26332 & 0,2703 \\
\hline
\end{tabular}

Fonte: Ipeadata. Disponível em: <http://www.ipeadata.gov.br>. Acesso em: 3 out. 2017.

Elaboração dos autores. 
A tabela 5 mostra um número ótimo de sete defasagens, indicados pelos critérios LR, FPE, AIC e HQ, para os valores em diferença, com 189 observaçóes. $\mathrm{Na}$ tabela 6, com relação ao teste de Granger, verifica-se que a primeira hipótese, HO: D(Renda) does not Granger Cause D(Gini), é rejeitada e a segunda hipótese, H0: D(Gini) does not Granger Cause D(Renda), não é rejeitada. Assim, como resultado final, pode-se concluir que há uma causalidade que vai da renda para a desigualdade, confirmando o resultado anterior.

No contexto supracitado, pode-se argumentar que é imprescindível que se conheça os mecanismos que estão imbricados no crescimento, na desigualdade e como estes se inter-relacionam. Conforme destaca Diniz (2005), há informaçóes, características e tendências na renda ou no crescimento econômico que ajudam na predição da desigualdade, tornando ainda mais claro o fato de que qualquer política pública que vise alterar o ciclo do crescimento ou a sua intensidade trará repercussão sobre o comportamento da desigualdade. Há evidências de que a eficiência econômica e a equidade estabelecem vínculos de múltiplas formas, constituindo uma rede complexa de relaçóes entre essas variáveis.

Kumar (2005) é enfático em dizer que a realidade brasileira guarda sintonia com os processos de desenvolvimento, ou de "causação circular cumulativa", conforme defendido por Myrdal (1957). Para Kumar (2005), quando os governos dão ênfase às políticas de crescimento sem considerar o combate à desigualdade como objetivo central, o efeito mais imediato não é o de superação das desigualdades, mas, sim, do seu aprofundamento. A maioria das atividades de natureza econômica que guardam relação com o crescimento, como artes, educação, saúde, geração de emprego, agências bancárias, floresce onde já se evidencia algum grau de desenvolvimento, pois nessas áreas já existem as pré-condiçóes necessárias de apoio à dinâmica desses empreendimentos. Nesse sentido, a açâo do Estado no estabelecimento de políticas públicas que neutralizem os efeitos não desejados da causação cumulativa pode interromper essa trajetória de desigualdade. Os resultados da tabela 7, obtidos a partir do modelo econométrico anteriormente apresentado, permitem aprofundar essa discussão.

Nessa estimativa, busca-se identificar o modelo mais consistente e os resultados mais robustos. Para isso, as variáveis foram paulatinamente incorporadas na regressão até alcançar o modelo final, tomando a desigualdade como variável dependente e as demais variáveis de controle, como independentes. Todos os resultados foram significantes ao nível de $1 \%, 5 \%$ e $10 \%$ e todos os coeficientes apresentam os sinais esperados. 
TABELA 7

Estimativas de painel com efeitos fixos (1999-2014) ${ }^{1}$

\begin{tabular}{|c|c|c|c|c|c|}
\hline Variáveis & Modelo 1 & Modelo 2 & Modelo 3 & Modelo 4 & Modelo 5 \\
\hline Constante & $\begin{array}{r}0,96981 \\
\left(0,07191^{*}\right)\end{array}$ & $\begin{array}{r}0,83365 \\
\left(0,06306^{*}\right)\end{array}$ & $\begin{array}{r}0,50188 \\
\left(0,05047^{*}\right)\end{array}$ & $\begin{array}{r}0,61038 \\
\left(0,05209^{*}\right)\end{array}$ & $\begin{array}{r}0,62626 \\
\left(0,05252^{*}\right)\end{array}$ \\
\hline Renda & $\begin{array}{r}-0,00117 \\
\left(0,00022^{*}\right)\end{array}$ & $\begin{array}{r}-0,00096 \\
\left(0,00019^{*}\right)\end{array}$ & $\begin{array}{r}-0,00076 \\
\left(0,00014^{*}\right)\end{array}$ & $\begin{array}{r}-0,00034 \\
\left(0,00015^{\star *}\right)\end{array}$ & $\begin{array}{r}-0,00042 \\
\left(0,00016^{\star * *}\right)\end{array}$ \\
\hline$(\text { Renda })^{2}$ & $\begin{array}{r}8,74 \mathrm{E}-07 \\
\left(1,71 \mathrm{E}-07^{*}\right)\end{array}$ & $\begin{array}{r}7,68 \mathrm{E}-07 \\
\left(1,48 \mathrm{E}-07^{*}\right)\end{array}$ & $\begin{array}{r}6,65 \mathrm{E}-07 \\
\left(1,10 \mathrm{E}-07^{*}\right)\end{array}$ & $\begin{array}{r}4,16 \mathrm{E}-07 \\
\left(1,14 \mathrm{E}-07^{* *}\right)\end{array}$ & $\begin{array}{r}4,69 \mathrm{E}-07 \\
\left(1,17 \mathrm{E}-07^{*}\right)\end{array}$ \\
\hline$D(I P C A)$ & $\begin{array}{r}0,00391 \\
\left(0,00075^{*}\right)\end{array}$ & $\begin{array}{r}0,00291 \\
\left(0,00065^{*}\right)\end{array}$ & $\begin{array}{r}0,00151 \\
\left(0,00049^{* *}\right)\end{array}$ & $\begin{array}{r}0,00222 \\
\left(0,00048^{*}\right)\end{array}$ & $\begin{array}{r}0,00234 \\
\left(0,00049^{\star}\right)\end{array}$ \\
\hline Npobres & & $\begin{array}{r}2,45 \mathrm{E}-08 \\
\left(2,13 \mathrm{E}-09^{*}\right)\end{array}$ & $\begin{array}{r}8,38 \mathrm{E}-09 \\
\left(1,83 \mathrm{E}-09^{*}\right)\end{array}$ & $\begin{array}{r}5,68 \mathrm{E}-09 \\
\left(1,82 \mathrm{E}-09^{* *}\right)\end{array}$ & $\begin{array}{r}5,07 \mathrm{E}-09 \\
\left(1,84 \mathrm{E}-09^{* * *}\right)\end{array}$ \\
\hline Ginformalidad & & & $\begin{array}{r}0,00454 \\
\left(0,00025^{*}\right)\end{array}$ & $\begin{array}{r}0,00306 \\
\left(0,00036^{*}\right)\end{array}$ & $\begin{array}{r}0,00290 \\
\left(0,00036^{*}\right)\end{array}$ \\
\hline Educação & & & & $\begin{array}{r}-0,02887 \\
\left(0,00507^{\star}\right)\end{array}$ & $\begin{array}{r}-0,02652 \\
\left(0,00519^{*}\right)\end{array}$ \\
\hline TXmorinf & & & & & $\begin{array}{r}0,000414 \\
\left(0,00021^{* * *}\right)\end{array}$ \\
\hline R2 & 0,10686 & 0,33936 & 0,637335 & 0,666386 & 0,66978 \\
\hline R2 - ajustado & 0,03780 & 0,286367 & 0,607194 & 0,637688 & 0,640414 \\
\hline Estatística F & 1,547274 & 6,403918 & 21,14511 & 23,22070 & 22,80348 \\
\hline Probabilidade da estatística F & $<0,00001$ & $<0,00001$ & $<0,00001$ & $<0,00001$ & $<0,00001$ \\
\hline
\end{tabular}

Fonte: Ipeadata. Disponivel em: <http://www.ipeadata.gov.br>. Acesso em: 3 out. 2017.

Elaboração dos autores.

Nota: ' Variável dependente: Gini.

Obs.: Valores do desvio-padrão entre parênteses. $\left({ }^{*}\right)$ p_valor $<0,01 ;\left(^{* *}\right) 0,001<$ p_valor $<0,05 ;\left(^{* * *}\right) 0,05<p$-valor $<0,10$.

Como esperado, os resultados empíricos da tabela 7 mostram uma relação diretamente proporcional entre a desigualdade e as seguintes variáveis: número de pobres, taxa de mortalidade infantil, taxa de inflaçáo e grau de informalidade. Por sua vez, também como esperado, a desigualdade apresenta uma relação inversamente proporcional à educação. Por fim, destaca-se uma relação não linear entre desigualdade e renda em forma de $\mathrm{U}$, denotando uma relação oposta àquela evidenciada pela curva de Kuznets.

A tabela 8 mostra estimativa de dados em painel com efeitos fixos ajustados com erro-padrão robusto que corrige possíveis problemas de heteroscedasticidade. Pode-se observar que os resultados são similares ao modelo 5 da tabela 7 . 
TABELA 8

Estimativa de painel com efeitos fixos ajustado com erro-padrão robusto (1999-2014) ${ }^{1}$

\begin{tabular}{lcccc}
\hline Variáveis & Coeficiente estimado & $\begin{array}{c}\text { Erro-padrão robusto } \\
\text { (fe vce robust) }\end{array}$ & Estatística $t$ & Valor da probabilidade \\
\hline Renda & $-0,00043$ & 0,00009 & $-4,78$ & $<0,00001$ \\
(Renda) $^{2}$ & $4,69 \mathrm{e}-07$ & $5,76 \mathrm{e}-08$ & 8,15 & $<0,00001$ \\
D(IPCA) & 0,00234 & 0,0003 & 6,62 & $<0,00001$ \\
Npobres & $5,07 \mathrm{e}-09$ & $1,31 \mathrm{e}-09$ & 3,87 & 0,001 \\
Ginformalidad & 0,00290 & 0,00059 & 4,88 & $<0,00001$ \\
Educação & $-0,02653$ & 0,00573 & $-4,63$ & $<0,00001$ \\
TXmortinf & 0,00041 & 0,00018 & 2,22 & 0,035 \\
Constante & 0,62626 & 0,04169 & 15,02 & $<0,00001$ \\
\hline
\end{tabular}

R2 within $=0,6698 \quad$ R2 Overall $=0,2774 \quad$ N Obs. $=405 \quad F(7,26)=466,50 \quad$ Prob $>F=<0,00001$

Fonte: Ipeadata. Disponível em: <http://www.ipeadata.gov.br>. Acesso em: 3 out. 2017.

Elaboração dos autores.

Nota: ${ }^{1}$ Variável dependente: Gini.

Obs.: Valores das variáveis em log.

A tabela 9 apresenta estimativa de dados em painel ajustados com erro-padrão robusto com efeitos fixos para as UFs e dummies para o período 1999-2014. Pode-se observar que os resultados são similares aos da tabela 8 , de forma que a inclusão de dummies temporais não altera a significância dos coeficientes estimados, nem os respectivos sinais, exceto para a variável educação.

TABELA 9

Estimativa de painel com efeitos fixos ajustado com erro-padrão robusto, e com dummies de tempo (1999-2014) ${ }^{1}$

\begin{tabular}{|c|c|c|c|c|}
\hline Variáveis & Coeficiente estimado & $\begin{array}{l}\text { Erro-padrão robusto } \\
\quad \text { (fe vce robust) }\end{array}$ & Estatística $t$ & Valor da probabilidade \\
\hline Renda & $-0,80755$ & 0,34790 & $-2,32$ & 0,028 \\
\hline$(\text { Renda })^{2}$ & 0,07474 & 0,02749 & 2,72 & 0,012 \\
\hline IPCA & 0,02090 & 0,00888 & 2,35 & 0,027 \\
\hline Npobres & 0,10652 & 0,01313 & 8,11 & $<0,00001$ \\
\hline Ginformalidad & 0,23666 & 0,07315 & 3,23 & 0,003 \\
\hline Educação & 0,04531 & 0,05870 & 0,77 & 0,447 \\
\hline TXmortinf & 0,05436 & 0,02025 & 2,68 & 0,012 \\
\hline Constante & $-1,25597$ & 1,12829 & $-1,11$ & 0,276 \\
\hline R2 within $=0,7313$ & R2 Overall $=0,1728$ & N Obs. $=432$ & $F(21,26)=105,98$ & Prob $>F=<0,00001$ \\
\hline
\end{tabular}

Fonte: Ipeadata. Disponível em: <http://www.ipeadata.gov.br>. Acesso em: 3 out. 2017.

Elaboração dos autores.

Nota:1 Variável dependente: Gini.

Obs: Valores das variáveis em log. 
A seguir, com base na tabela 10, nota-se a estimativa de dados em painel que utiliza o método FGLS, considerando-se que o termo do erro não é independente e identicamente distribuído. Esse método corrige possíveis problemas de autocorrelação, correlaçâo entre painéis e heterocedasticidade, conforme Davidson e MacKinnon (1993). Pode-se observar que os resultados são similares aos resultados anteriores. No apêndice A, utiliza-se esse mesmo método para mostrar que os resultados empíricos são similares ao utilizar dummies de tempo e por região, conforme as tabelas A.2 e A.3, respectivamente.

\section{TABELA 10}

Estimativa de painel via método FGLS (1999-2014) ${ }^{1}$

\begin{tabular}{lcccc}
\hline Variáveis & Coeficiente estimado & Erro-padrão & Estatística $t$ & Valor da probabilidade \\
\hline Renda & $-0,90762$ & 0,19711 & $-4,60$ & $<0,00001$ \\
${\text { (Renda })^{2}}^{\text {PCA }}$ & 0,08002 & 0,01467 & 5,45 & $<0,00001$ \\
Npobres & 0,02491 & 0,00886 & 2,81 & 0,00500 \\
Ginformalidad & 0,01600 & 0,00298 & 5,36 & $<0,00001$ \\
Educação & 0,20768 & 0,02964 & 7,01 & $<0,00001$ \\
TXmortinf & $-0,05068$ & 0,03344 & $-1,52$ & 0,13000 \\
\hline Constante & 0,10530 & 0,01474 & 7,14 & $<0,00001$ \\
\hline
\end{tabular}

Fonte: Ipeadata. Disponível em: <http://www.ipeadata.gov.br>. Acesso em: 3 out. 2017.

Elaboração dos autores.

Nota: 1 Variável dependente: Gini.

Obs.: Valores das variáveis em log. 0 painel FGLS corrige possíveis problemas de heteroscedasticidade e autocorrelação.

Na tabela 11, por meio de um painel dinâmico com o uso de instrumentos, busca-se testar a robustez dos resultados obtidos nas tabelas de 7 a 10, principalmente no que se refere ao comportamento das variáveis Renda e (Renda) ${ }^{2}$, o que permitirá inferir alguma conclusão mais consistente a respeito da hipótese do U invertido de Kuznets; foco principal deste estudo.

Nota-se que todas as estatísticas são significantes ao nível de 1\% e que a relação entre a desigualdade e as demais variáveis mantém a mesma lógica dos resultados anteriores. Quando se observam as variáveis Renda e (Renda) ${ }^{2}$, percebe-se que, para todos os modelos testados, a primeira variável apresenta um coeficiente com sinal negativo e a variável (Renda) ${ }^{2}$ mostra um sinal positivo. Esse comportamento é verificado para as estimativas das tabelas de 7 a 11, sinalizando uma relação não linear entre as variáveis. Isso leva à compreensão de que, inicialmente, a desigualdade cai quando a renda dos indivíduos aumenta e, em um momento posterior, quando esse aumento ultrapassa o ponto de mínimo da curva em forma de U, a desigualdade também cresce, evidenciando um comportamento oposto àquele demonstrado pela hipótese de Kuznets. 
Pode-se observar que a hipótese nula da estatística $J$, na qual os instrumentos utilizados são bons, não é rejeitada. Nesse contexto, os resultados empíricos sugerem que o modelo de crescimento que vigora na economia brasileira induz ao aumento da desigualdade a partir do ponto de mínimo da curva em forma de $\mathrm{U}$ da renda domiciliar. Por sua vez, os resultados também indicam que melhoras nos indicadores socioeconômicos podem mitigar o grau de desigualdade de renda no Brasil.

\section{TABELA 11}

Estimativa de painel dinâmico com o uso de instrumentos (1999-2014)1

\begin{tabular}{lcccc}
\hline Variáveis & Coeficiente estimado & Erro-padrão & Estatística $t$ & Valor da probabilidade \\
\hline Gini(-1) & 0,142107 & 0,028263 & 5,028042 & $<0,00001$ \\
Renda & $-0,000458$ & $3,55 \mathrm{E}-05$ & $-12,90351$ & $<0,00001$ \\
${\text { (Renda })^{2}}^{2}$ & $5,11 \mathrm{E}-07$ & $2,62 \mathrm{E}-08$ & 19,51777 & $<0,00001$ \\
IPCA & $-0,005066$ & 0,000185 & $-27,45626$ & $<0,00001$ \\
Npobres & $1,22 \mathrm{E}-08$ & $1,98 \mathrm{E}-09$ & 6,185163 & $<0,00001$ \\
Ginformalidad & 0,004359 & 0,000297 & 14,66341 & $<0,00001$ \\
Educação (-1) & $-0,010575$ & 0,000902 & $-11,72689$ & $<0,00001$ \\
TXmortinf & 0,001714 & 0,000425 & 4,027757 & 0,0001 \\
\hline
\end{tabular}

Cross-section E.F. (1 1 - diferença); Estatística J = 26,88; Probabilidade estatística J =0,11

Instrumentos: Gini (-2 a -5); TXmortinf (-1 a -5); Ginformalidad (-1 a -5); Educação (-1 a -5); @trend; ipca (-1 a -5); Npobres (-1 a -5); renda (-2 a -3); renda*educação; popocupada; popocupada (-1 a -5); popdesoc (-1 a -5)

Fonte: Ipeadata. Disponível em: <http://www.ipeadata.gov.br>. Acesso em: 3 out. 2017.

Elaboração dos autores.

Nota: ${ }^{1}$ Variável dependente: Gini.

Pode-se destacar também que a queda da desigualdade pode ter sido resultante de uma multiplicidade de fatores. A implementação do Plano Real a partir de 1993/1994 criou as condiçóes para a estabilidade do nível geral de preços de forma que o Brasil passou a conviver com taxas de inflação de um dígito. Nesse contexto, pode-se notar que maiores taxas de inflação afetam, de forma perversa, principalmente a população com menores faixas de renda por meio do imposto inflacionário. Com base nos resultados empíricos, evidencia-se que menores taxas de inflação contribuem para redução da desigualdade de renda.

Com a implementação do tripé macroeconômico a partir de 1999, com base no sistema de metas de inflação, responsabilidade fiscal e câmbio flexivel, os fundamentos macroeconômicos melhoraram. Com o boom das commodities, principalmente a partir de 2004, o Brasil colheu os benefícios do crescimento econômico mundial e dos bons fundamentos da economia. Aliadas aos aspectos macroeconômicos, as políticas de rendas implementadas desde o Plano Real foram relevantes para reduzir as desigualdades. Ressalta-se que tais políticas foram fortemente expandidas a partir dos anos 2000, por meio de programas sociais, como 
o PBF, o maior acesso ao crédito para os cidadãos de baixa renda, entre outros programas. No contexto supracitado, os indicadores sociais melhoraram e o grau de desigualdade reduziu-se. Dessa forma, com uma economia pujante e a expansão dos programas sociais, pode-se intuir que houve uma redução da economia informal, da pobreza e da taxa de mortalidade. As reduçôes desses três fatores em média também contribuíram para a redução da desigualdade no período analisado (1999-2014). As dummies por UFs, ano (de 1999 a 2014) e região podem ter captado parte das consideraçôes aqui já citadas no que diz respeito aos aspectos macroeconômicos e aos programas e políticas sociais e de renda.

\section{CONSIDERAÇÕES FINAIS}

Este trabalho investiga a relação entre crescimento econômico e desigualdade de renda, testando a validade da hipótese de Kuznets para as 27 UFs do Brasil, a partir de um painel de dados com frequência anual, compreendendo o período 1999-2014.

Os procedimentos metodológicos são aplicados em duas etapas. Na primeira etapa, aplica-se o teste de causalidade de Granger para as variáveis de interesse: o índice de Gini, medindo a desigualdade, e a renda domiciliar per capita média, mensurando o crescimento econômico. Na segunda, fazem-se estimativas de painel com efeitos fixos e aleatórios (FGLS), além de painel dinâmico com o uso de instrumentos estabelecendo o indicador de desigualdade de renda como variável dependente em função da renda per capita, educação, inflação do IPCA, pobreza, informalidade e mortalidade infantil.

Para os dois testes de causalidade realizados, com os valores em nível e com os valores em diferença, os resultados foram iguais. Eles apontam uma causalidade que vai do crescimento econômico para a desigualdade. Esses resultados confirmam a relação de interdependência entre essas duas variáveis, sinalizando uma tendência de influência que parte do crescimento para a desigualdade. $\mathrm{Na}$ investigação de Kuznets, a desigualdade assume uma trajetória de queda somente quando o crescimento atinge certo patamar de maturidade, sendo puxado pelos setores mais dinâmicos e industrializados da economia, com ênfase no aumento da produtividade. Dessa forma, a curva de Kuznets possui a forma de um U invertido. Os nossos resultados empíricos mostram também uma relação não linear entre crescimento de renda e desigualdade, mas na forma de um U.

Nesse contexto, os resultados empíricos indicam que, para o conjunto dos estados brasileiros e no período considerado, a hipótese da curva do U invertido de Kuznets náo é validada para o caso do Brasil. Com base na hipótese de Kuznets, a desigualdade aumenta nos momentos iniciais do crescimento até o ponto em que a economia atinge certo patamar de maturidade e, depois, decresce com a potencialidade desse crescimento. Os resultados aqui expostos mostram um movimento 
contrário. Isto é, a desigualdade cai um pouco com os primeiros movimentos do crescimento e, depois, volta a crescer, como consequência desse crescimento.

Assim, retomando as duas questóes centrais expostas no início desta pesquisa, pode-se concluir que: $i$ ) a relação que prevalece entre crescimento econômico e desigualdade de renda é uma relação unicausal que parte do crescimento para a desigualdade; e ii) a hipótese da curva do U invertido de Kuznets não é válida para explicar o comportamento da desigualdade brasileira para o período considerado (1999-2014).

Pode-se ressaltar que a economia brasileira possui sérias restriçôes, sejam conjunturais, sejam estruturais, para obter uma taxa de crescimento econômico sustentável no longo prazo. Para enfatizar as características peculiares da economia brasileira, podem-se destacar algumas consideraçóes sobre essa questão. Para Oreiro e Marconi (2014), a participação de produtos manufaturados na pauta exportadora vem apresentando uma forte tendência de queda desde 2005, tendo sido superada pela participação dos produtos primários a partir de 2009. Esse mesmo viés é verificado quando se analisa a composição da pauta exportadora dos produtos por intensidade tecnológica. Os produtos de alta e média tecnologia começam a perder importância a partir de meados dos anos 2000, denotando uma tendência de que o Brasil volte a ser uma economia primário-exportadora.

Para Kruglianskas e Pereira (2005), a realidade da economia brasileira é resultado de um modelo de crescimento que não criou condiçôes e estímulos favoráveis à produção de ciência e tecnologia $(\mathrm{C} \& \mathrm{~T})$, as quais são necessárias à dinamização da indústria e à competividade. A produção de ciência, apesar de ser reconhecida, não consegue interagir em um nível adequado com os setores produtivos, fazendo com que os produtos nacionais continuem mostrando pouco valor agregado e baixa tecnologia.

Além desses fatores, alertam Pinheiro et al. (2007), o Brasil precisa criar instrumentos e desenvolver estratégias referentes à qualidade do ajuste fiscal, ao controle dos gastos públicos e das taxas de inflação, à qualidade da burocracia estatal, com combate à ineficiência e à corrupçáo no setor público, além de conceder significativos investimentos em capital humano. Sem essas providências, o país continuará no topo do ranking da pobreza e da desigualdade, puxado por um padrão de crescimento que não consegue tirá-lo da condição de país emergente.

É possível que os modelos de crescimento que têm sido adotados no Brasil apresentem restrições socioeconômicas, institucionais e históricas de forma que não se ajustam às experiências de países desenvolvidos, pois a economia brasileira no período considerado mostra uma relação entre desigualdade e renda oposta ao dos países desenvolvidos, ao apresentar uma curva na forma de U. Nesse contexto, a trajetória da relação entre crescimento e desigualdade no Brasil ainda não é capaz 
de impor à desigualdade uma trajetória de queda sustentável ou consistente. Pelas evidências aqui expostas, ainda não há sinais de que, no curto prazo, essa realidade seja modificada.

Possivelmente, a partir de 2014, pode-se observar uma estagnação ou um aumento da taxa de desigualdade de renda em função da forte crise econômica e da fraca e lenta recuperação da economia brasileira. Admitindo-se que o país se situa na vizinhança do ponto de mínimo da curva em forma de $U$ ou à esquerda desse ponto, as taxas negativas de crescimento econômico podem levar ao aumento da desigualdade de renda.

Considerando-se que o Brasil ainda não criou as condiçóes para um processo de crescimento sustentável de longo prazo, é como se a economia brasileira operasse com taxas de crescimento que se movimentam de forma pendular, tal que abrangesse valores bem mais à esquerda do ponto de mínimo até um pouco mais à sua direita. Esse argumento faz sentido, pois, ao longo do período analisado (1999-2014), houve crescimento econômico com redução da desigualdade. Nesse contexto, pode-se fazer uma análise pelo contraditório: admitindo-se que o país, no período analisado, estivesse à direita do ponto do mínimo. Nesse caso, ocorreria aumento de crescimento com incremento da desigualdade. Os gráficos 1 e 2 mostram, ao comparar por regiāo o ano de 1999 com o de 2014, que houve redução da desigualdade, assim como aumento da renda domiciliar em todas as regióes.

\section{REFERÊNCIAS}

AHLUWALIA, M. Income distribution and development: some stylized facts. American Economic Review, v. 66, p. 128-153, 1976.

BAGOLIN, I.; GABE, J.; RIBEIRO, I. Crescimento e desigualdade no Rio Grande do Sul: uma revisão da curva de Kuznets para os municípios gaúchos (1970-1991). In: ENCONTRO DE ECONOMIA GAÚCHA, 2., 2004, Porto Alegre. Anais... Porto Alegre: PUCRS; FEE, 2004. Disponível em: <https://bit.ly/2DH8k5d>. Acesso em: 30 nov. 2016.

BALTAGI, B. Econometric Analysis of Panel Data. 5 ed. New Jersey: Wiley, 2013.

BARRO, R. Inequality and growth in a panel of countries. Journal of Economic Growth, v. 5, p. 5-32, 2000.

BARROS, L. C.; GOMES, F. A. R. Desigualdade e desenvolvimento: a hipótese de Kuznets é válida para os municípios brasileiros? Revista Análise Econômica, Porto Alegre, v. 26, n. 50, p. 57-81, set. 2008.

BÊRNI, D.; MARQUETTI, A.; KLOECKMER, R. A desigualdade econômica do Rio Grande do Sul: primeiras investigaçóes sobre a curva de Kuznets. In: 
ENCONTRO DE ECONOMIA GAÚCHA, 1., 2002, Porto Alegre. Anais... Porto Alegre, 2002.

DAVIDSON, R.; MACKINNON, J. G. Estimation and inference in econometrics. New York: Oxford University Press, 1993.

DINIZ, M. B. Contribuiçóes ao estudo da desigualdade de renda entre os estados brasileiros. 2005. Tese (Doutorado) - Faculdade de Economia, Universidade Federal do Ceará, Fortaleza, 2005.

FIGUEIREDO, E.; SILVA JUNIOR, J.; JACINTO, P. A hipótese de Kuznets para os municípios brasileiros: testes para as formas funcionais e estimaçóes não paramétricas. Revista Economia, Brasília, v. 12, n. 1, p. 149-165, abr. 2011.

GLAESER, E. Inequality. NBER Working Paper Series, Oct. 2005. (Working Paper, n. 11511). Disponível em: <https://bit.ly/3hntvb1>. Acesso em: 15 maio 2016.

GRANGER, C. W. J.; HUANG, L. Evaluation of panel data models: some suggestions from time series. San Diego: U.C. San Diego, 1997. Mimeograf.

GRÜNDLER, K.; SCHEUERMEYER, P. Income inequality, economic growth and the effect of redistribution. University of Würzburg, out. 2014.

HOLTZ-EAKIN, D.; NEWEY, W.; ROSEN, H. Estimating vector autoregressions with panel data. Econometrica, v. 56, p. 1371-1395, 1988.

HSING, Y.; SMITH, D. Kuznets' inverted-U hypothesis revisited. Applied economic letters, v. 8, p. 2-111, nov. 1994.

HUANG, H. et al. A quantile inference of the Kuznets hypothesis. Economic Modelling, n. 24, v. 3, p. 24-559, 2007.

HURLIN, C. Un test simple de l'Hypothèse de non causalité dans un modèle de panel hétérogène. Revue Economique, v. 56, n. 3, p. 799-809, 2005.

IPEA - INSTITUTO DE PESQUISA ECONÔMICA APLICADA. Dimensão, evoluçáo e projeção da pobreza por regiáo e por estado no Brasil. Brasília: Ipea, jul. 2010.

JACINTO, P.; TEJADA, C. Desigualdade de renda e crescimento econômico nos municípios da regiáo nordeste do Brasil: o que os dados têm a dizer? In: ENCONTRO NACIONAL DE ECONOMIA, 32., 2004, João Pessoa. Anais... João Pessoa: Anpec, 2004. Disponível em: <https://bit.ly/3fNavSY>.

JANNUZZI, P. M. Pobreza, desigualdade e mudança social: trajetória no Brasil crescente de 1992 a 2014. Revista de Estudos e Pesquisas sobre as Américas, v. 10, n. 3, 2016. 
KRUGLIANSKAS, I.; PEREIRA, M. J. Um enfoque sobre a Lei de Inovação Tecnológica do Brasil. Revista de Administraçáo Pública, v. 39, n. 5, p. 1011 1029, 2005.

KUMAR, A. Access to financial services in Brazil. Washington: The World Bank, 2005. 619 p.

KUZNETS, S. Economic growth and income inequality. American Economic Association, v. 45, n. 1, p. 1-28, mar. 1955.

. Crescimento econômico moderado. São Paulo: Abril Cultural, 1983.

LINHARES, F. et al. A hipótese de Kuznets e mudanças na relação entre desigualdade e crescimento de renda no Brasil. Pesquisa e planejamento econômico, v. 42, n. 3, p. 403-430, dez. 2012.

LUNDBERG, M.; SQUIRE, L. Novas evidências sobre desigualdade, pobreza e crescimento. In: TEOFILO, E. (Org.) Distribuição de riqueza e crescimento econômico. Brasília: MDA, 2000. 200 p.

MENDES, M. Por que o Brasil cresce pouco? Desigualdade, democracia e baixo crescimento no país do futuro. Rio de Janeiro: Elsevier, 2014.

MYRDAL, G. Economic theory and under developed regions. London: Duckworth Press, 1957.

MUSHINSKI, D. Using non-parametrics to inform parametric tests of Kuznet's. Applied Economic Letters, v. 8, n. 1, p. 77-79, set. 2001.

OREIRO, J. L.; MARCONI, N. Teses equivocadas sobre desindustrialização e perda de competitividade da indústria brasileira. Revista Necat, n. 5, jan/jun. 2014.

OSTRY, J.; BERG, C.; TSANGARIDES, C. G. Redistribution, inequality, and growth. IMF Staff discussion note, Feb. 2014.

PIKETTY, T. A economia da desigualdade. Rio de Janeiro: Intrínseca, 2015.

PINHEIRO, M. C. et al. Por que o Brasil náo precisa de política industrial. Rio de Janeiro: FGV, 2007. (Texto para Discussão, n. 644).

PNUD - PROGRAMA DAS NAÇÓES UNIDAS PARA O DESENVOLVIMENTO. Síntese do Relatório do Desenvolvimento Humano. PNUD, 2013. Disponível em: <https://bit.ly/2ZNxJ5L >

Relatório do Desenvolvimento Humano 2015: o trabalho como motor do desenvolvimento humano. PNUD, 2015. Disponível em: <https://bit. ly/2E7egVv>. 
SALVATO, M. et al. Crescimento e desigualdade: evidências da curva de Kuznets para os municípios de Minas Gerais. Belo Horizonte: Ibmec, 2006. (Working Paper, n. 33). Disponível em: <https://bit.ly/2FDkcq2>.

SANTOS, A.; JACINTO, P.; TEJADA, C. Causalidade entre renda e saúde: uma análise através da abordagem de dados em painel com os estados do Brasil. Estudos Econômicos, São Paulo, v. 42, n. 2, p. 229-261, jun. 2012.

SANTOS, L.; MIRANDA, R.; MOREIRA, T. A pobreza no Brasil e as estratégias de superaçáo. Revista de economia e agronegócio, Viçosa, v. 10, n. 3, p. 359395, dez. 2012.

SIMS, C. A. Money, income and causality. American Economic Review, n. 62, p. 540-552, 1980.

THORNTON, J. The Kuznets inverted-U hypothesis: panel data evidence from 96. Countries. Applied Economics Letters, v. 8, p. 15-16, 2001.

WOOLDRIDGE, J. M. Econometric analysis of Cross Section and Panel Data. Massachusetts: MIT Press, 2002.

\section{BIBLIOGRAFIA COMPLEMENTAR}

ARBACHE, J. S. Pobreza e mercados no Brasil: uma análise de iniciativas de políticas públicas. Brasília: Cepal; DFID, 2003.

GAFAR, J. Growth, inequality and poverty in selected Caribbean and Latin America countries, with emphasis on Guyana. Journal of Latin America Studies, v. 30, n. 591-617, 1998.

RAVAILLON, M. Growth, inequality and poverty: looking beyond averages. Washington: World Bank, 2001. (Working Paper, n. 2558). 


\section{APÊNDICE A}

TABELA A. 1

Testes de raiz unitária Levin-Lin-Chu

\begin{tabular}{lcc}
\hline Variáveis & Estatística: $t$ não ajustado e $(t$ ajustado $)$ & P-valor \\
\hline Log (Gini) & $-17,60(-5,37)$ & $<0,00001$ \\
$\log ($ Renda) & $-10,29(-3,16)$ & 0,0008 \\
$\log (\text { Renda })^{2}$ & $-10,15(-2,75)$ & 0,0030 \\
$\log (\Delta \mathrm{PPCA})^{2}$ & $-18,79(-11,90)$ & $<0,00001$ \\
$\log ($ N_de_pobres) & $-18,51(-12,52)$ & $<0,00001$ \\
$\log ($ G_informalidad) & $-20,28(-11,82)$ & $<0,00001$ \\
$\log ($ Educação) & $-8,58(-2,38)$ & 0,0087 \\
$\log ($ TX_mortinfantil) & $-53,54(-55,85)$ & $<0,00001$ \\
\hline
\end{tabular}

Fonte: Ipeadata. Disponível em: <http://www.ipeadata.gov.br>. Acesso em: 3 out. 2017.

Elaboração dos autores.

Notas: ${ }^{1}$ Com tendência.

${ }^{2}$ A diferença do Índice Nacional de Preços ao Consumidor Amplo (IPCA) foi somada a um dado valor positivo (5) para tornar $\triangle \mathrm{IPCA}>0$. Ho: Painel contém raiz unitária. Regressões ADF.

Obs.: 1. Dados em painel.

2. ADF = Augmented Dickey-Fuller test statistic (estatística de teste Dickey-Fuller aumentada).

TABELA A.2

Estimativa pelo método painel FGLS com efeitos fixos (1999-2014) ${ }^{1}$

\begin{tabular}{|c|c|c|c|c|}
\hline Variáveis & Coeficiente estimado & Erro-padrão & Estatística $t$ & Valor da probabilidade \\
\hline Constante & 1,03948 & 0,67095 & 1,55 & 0,12100 \\
\hline Renda & $-0,87634$ & 0,16920 & $-5,18$ & $<0,00001$ \\
\hline$(\text { Renda })^{2}$ & 0,08272 & 0,01258 & 6,61 & $<0,00001$ \\
\hline IPCA & $-0,65323$ & 0,16027 & $-4,08$ & $<0,00001$ \\
\hline Npobres & 0,01677 & 0,00254 & 6,58 & $<0,00001$ \\
\hline Ginformalidad & 0,26628 & 0,02592 & 10,27 & $<0,00001$ \\
\hline Educação & $-0,02335$ & 0,03035 & $-0,77$ & 0,44200 \\
\hline TXmorinf & 0,12564 & 0,01419 & 8,42 & $<0,00001$ \\
\hline
\end{tabular}

Fonte: Ipeadata. Disponível em: <http://www.ipeadata.gov.br>. Acesso em: 3 out. 2017.

Elaboração dos autores.

Nota: ${ }^{1}$ Variável dependente: Gini.

Obs.: Variáveis em log. 0 painel de estimação de mínimos quadrados generalizados factíveis (FGLS) corrige possiveis problemas de heteroscedasticidade e autocorrelação. As dummies de tempo de 1999 a 2012 foram todas estatisticamente significantes. 
A Hipótese de Kuznets para os Estados Brasileiros: evidências empíricas de dados em painel para o período 1999-2014

TABELA A.3

Estimativa pelo método painel FGLS com efeitos fixos para regiões (1999-2014)

\begin{tabular}{lcrcr}
\hline Variáveis & Coeficiente estimado & Erro-padrão & Estatística $t$ & Valor da probabilidade \\
\hline Renda & $-0,000059$ & 0,0000334 & $-1,74$ & 0,083 \\
${\text { (Renda })^{2}}_{\text {IPCA }}^{4,76 e-08}$ & $1,24 \mathrm{e}-08$ & 3,85 & $<0,0001$ \\
Npobres & 0,0023455 & 0,0007211 & 3,25 & 0,001 \\
Ginformalidad & $1,58 \mathrm{e}-09$ & $1,06 \mathrm{e}-09$ & 1,49 & 0,135 \\
Educação & 0,001211 & 0,0002921 & 4,15 & $<0,0001$ \\
TXmortinf & $-0,003783$ & 0,003421 & $-1,11$ & 0,269 \\
Sul & 0,001169 & 0,0002944 & 3,97 & $<0,0001$ \\
Sudeste & $-0,013971$ & 0,007784 & $-1,79$ & 0,073 \\
Centro-0este & $-0,012649$ & 0,006926 & $-1,83$ & 0,068 \\
Norte & $-0,013754$ & 0,0063844 & $-2,15$ & 0,031 \\
Constante & $-0,008945$ & 0,0049294 & $-1,81$ & 0,070 \\
\hline
\end{tabular}

Fonte: Ipeadata. Disponível em: <http://www.ipeadata.gov.br>. Acesso em: 3 out. 2017.

Elaboração dos autores.

Nota: ${ }^{1}$ Variável dependente: Gini.

Obs.: Variáveis em log. 0 painel FGLS corrige possíveis problemas de heteroscedasticidade e autocorrelação.

Data de submissão: 19/12/2017

Primeira decisão editorial em: 19/7/2018

Última versão recebida em: 23/10/2018

Aprovação final em: 7/11/2018 
